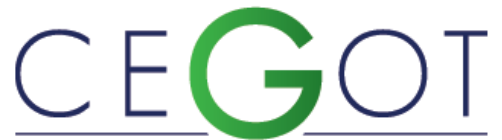

Centro de Estudos de Geografia e Ordenamento do Território
Geografia e Ordenamento do Território, Revista Eletrónica Centro de Estudos de Geografia e Ordenamento do Território http://cegot.org

Ultramari, Clóvis

Pontifícia Universidade Católica do Paraná, Programa de PósGraduação em Gestão Urbana (PPGTU) / Universidade Federal do Paraná, Programa de Pós-Graduação em Meio Ambiente e Desenvolvimento

PUCPR, Av. Imaculada Conceição, 1155, CEP80215-901, Curitiba, Brasil. ultramari@yahoo.com

\author{
VIANNA, FABIANO \\ Pontifícia Universidade Católica do Paraná, Curso de \\ Arquitetura e Urbanismo / Instituto de Pesquisa e Planejamento \\ Urbano de Curitiba (IPPUC) \\ PUCPR, Av. Imaculada Conceição, 1155, CEP80215-901, Curitiba, Brasil. \\ fabiano.vianna@pucpr.br \\ FIRMINO, RODRIGO \\ Pontifícia Universidade Católica do Paraná, Programa de Pós- \\ Graduação em Gestão Urbana (PPGTU) \\ PUCPR, Av. Imaculada Conceição, 1155, CEP80215-901, Curitiba, Brasil. \\ rodrigo.firmino@pucpr.br
}

\section{Camillo Sitte e Le Corbusier: colisão de críticas e aproximação de princípios}

Referência: Ultramari, Clóvis; Vianna, Fabiano; Firmino, Rodrigo (2018). Camillo Sitte e Le Corbusier: colisão de críticas e aproximação de princípios. Revista de Geografia e Ordenamento do Território (GOT), n. ${ }^{\circ} 15$ (dezembro). Centro de Estudos de Geografia e Ordenamento do Território, p. 481-503, dx.doi.org/10.17127/got/2018.15.020

\title{
RESUMO
}

Tem-se aqui uma revisão comparada entre visões de urbanismo comumente tidas como seminais e antagônicas, cujos valores sintetizariam importantes correntes do urbanismo: Der Städtebau nach seinen künstlerischen Grundsätzen, de Camillo Sitte, de 1889, e Manière de penser l'urbanisme (1924) e Urbanisme (1925), ambos de Le Corbusier. As teses defendidas aqui são de que: (1) há permanências e envelhecimentos de ambas as visões em nossas cidades contemporâneas, seja no campo das ideias, seja no campo das intervenções; e (2) críticas feitas a cada uma delas merecem ser relativizadas para corresponder ao conteúdo de seus originais. $\mathrm{O}$ artigo está estruturado em forma de ensaio e serve-se, para além da leitura das obras originais, de trabalhos que as discutem.

Palavras-chave: Camillo Sitte, Le Corbusier, Teoria do Urbanismo.

\section{ABSTRACT}

This is a review essay that aims to compare two idealizations of urbanism commonly taken as paradoxical. This is carried out through the critical reading of two works that, beyond their intrinsic values, are seminal for summarizing important ideas in the history of urbanism: Der Städtebau nach seinen künstlerischen Grundsätzen, by Camillo Sitte (1889) and Manière de penser I'urbanisme (1924), and Urbanism (1925) both by Le Corbusier. Theses defended in this paper are: (1) there are reminiscences and aging of both visions in 
our contemporary cities, both at the theoretical level as well as at the concrete one; and (2) critiques made to each of them may be relativized. This paper is developed as an essay and refers, besides to the reading of the original works, to other analyses, mostly those based on comparative methods.

Keywords: Camillo Sitte, Le Corbusier, Urbanism Theory.

\section{Introdução}

Este artigo resulta da leitura comparativa das obras Der Städtebau nach seinen künstlerischen Grundsätzen, de Camillo Sitte $(1889)^{1}$, e Manière de penser l'urbanisme (1924), e Urbanisme (1925), ambas por Le Corbusier², recorrentes no debate sobre a cidade contemporânea. A base teórica principal para essa leitura é o esforço de classificação tipológica encontrado em $O$ Urbanismo, utopias e realidades: uma antologia, de Françoise Choay (2005, primeira edição 1965). Essa referência estabelece, de pronto, uma colisão entre as ideias ditas progressistas de Le Corbusier, onde a geometria e a perspectiva apresentam-se como verdades salvadoras do espaço, e aquelas ditas culturalistas, conforme defendido por Camillo Sitte, para quem a irregularidade dos traçados e a espontaneidade da formação da cidade se apresentam como elementos necessários para a humanização do espaço vivido. De um lado, quase meio século após as intervenções de Haussmann em Paris, tem-se o arquiteto austríaco Sitte defendendo a simetria do pictórico; de outro, tem-se a defesa da funcionalidade da linha por Le Corbusier, anunciando o início de um longo processo de consolidação do movimento modernista.

Levantamento elaborado para a realização deste artigo junto a dois importantes bancos de teses e dissertações norte-americanos e um brasileiro ${ }^{3}$ confirmam: um persistente interesse recebido por Le Corbusier e Camillo Sitte; um incremento desse interesse ao longo do

\footnotetext{
${ }^{1}$ Com título em português $A$ Construção das Cidades segundo seus Princípios Artísticos, (Editora Ática: São Paulo, 1992) e em inglês City Planning according to Artistic Principles (Editora: Dover Publications, Inc.: Mineola, New York, 2006). A versão adotada neste artigo é a em inglês, publicada a partir da original austríaca. ${ }^{2}$ Com títulos em português Planejamento Urbano (Editora Perspectiva: São Paulo, 2013) e Urbanismo (Editora Martins Fontes: São Paulo, 1992). As versões adotadas neste artigo são as em português.

${ }^{3}$ Networked Digital Library of Theses and Dissertations (NDLTD), da Virginia Tech University / VA; Open Access Theses and Dissertations (OATD), da Associação de instituições acadêmicas norte-americanas; e Banco de Teses e Dissertações da Coordenação de Aperfeiçoamento de Pessoal de Nível Superior (CAPES). Vide Referências.
} 
tempo; uma esperada maior influência de Le Corbusier; e a presença significativa em ambos os resultados do Brasil como destaque de local onde essa produção científica se realiza.

No caso de Sitte, esse reconhecimento parece ter sido apreendido por ele próprio, já no prefácio da segunda edição de seu livro, relatando uma popularidade editorial:

Algumas semanas após a publicação, o livro já está completamente esgotado na editora. Esta é uma prova gratificante de que o tema em discussão gerou interesse. Entretanto, como opiniões professionais ainda não foram ouvidas e a expansão da publicação não me tenha sido enviada por alguma razão, esta segunda edição surge em formato totalmente inalterado (Sitte, 2006: 142). Tradução da versão em inglês pelos autores. ${ }^{4}$

Ao mesmo tempo em que as obras selecionadas para este ensaio são recorrentemente referenciadas, muitas vezes de modo paradoxalmente complementar em sugestões da cidade ideal, sugerem visões opostas, constituindo o que chamamos, a princípio, de ideias em colisão. O objeto olhado por esses dois autores e mesmo as referências utilizadas por eles é a mesma: a cidade industrial, ainda em seu estado prematuro. Na colisão das ideias, a oposição entre um urbanismo que se propõe a acompanhar e liderar tendências observadas em outros campos do conhecimento e outro que se submete a mudanças, mas referenciando o passado. Estão aí estabelecidas as distinções entre rejeitar, submeter-se ou aliar-se a modos sociais, culturais e políticos, sobretudo entre a defesa da forma ou da função, da estética ou da técnica, da natureza ou do artificial, do bucólico ou da velocidade, do rural ou do urbano, do vilarejo ou da cidade protagonista da sociedade do consumo. $\mathrm{Na}$ perspectiva da cidade contemporânea, estamos marcados e atraídos por uma ou outra dessas distinções, ou melhor, pela miscigenação delas. Novamente, Sitte vislumbra aquilo que agora observamos:

Discussões sobre o sistema de planeamento de cidades figura como um dos assuntos de interesse da atualidade. Sobre ele, assim como para outros tópicos, as opiniões divergem com frequência. No entanto, pode-se observar uma grande satisfação com aquilo que se tenha feito com as linhas retas - em relação ao tráfego, o vantajoso uso de terrenos e especialmente as melhorias na higiene urbana. Em contraste, há quase uma prevalência da condenação das simplificações artísticas do planejamento moderno, até mesmo um desprezo. Isso é justificável; é um fato que muito se fez a partir de uma perspectiva técnica, enquanto artisticamente avançamos quase nada. Edifícios modernos e majestosos são comumente contrapostos a bizarras praças e a um parcelamento erroneamente

\footnotetext{
${ }^{4} \mathrm{~A}$ few weeks after its publication, the book is already completely unavailable at the publisher's. This is gratifying proof that the subject under discussion has elicited a keen interest. However as professional opinions have not yet been heard and as expansion of the material does not seem warranted to me for any other reason, this second edition appears in completely unaltered form.
} 
projetado (Sitte, 2006: 138, prefácio da primeira edição). Tradução da versão em inglês pelos autores ${ }^{5}$.

Nas cidades contemporâneas, haveria então um urbanismo mestiço, positivamente tendendo para um outro lado, ao contrário do contexto de uma era de extremos (Hobsbawn, 2000) que certamente influenciou a elaboração das obras aqui discutidas e nas práxis de urbanismos emergentes, distinguindo "a razão e a contenção iluminista francesa e o ímpeto, a paixão, o desejo e o idealismo romântico alemão" (França, 2012: 50). Numa arriscada digressão, tais extremos poderiam ser visualizados em Morte em Veneza (Thomas Mann, 2000, primeira edição 1912), o qual estabelece a clara distinção entre racionalidade/espontaneidade, futuro/passado e estética/paixão/razão.

Neste cenário de opostos, desenvolve-se o presente ensaio, o qual finaliza com a observação de envelhecimentos e permanências daquilo defendido nas obras analisadas e com uma redução na distância ideológica que anteriormente se havia acreditado existir.

\section{Os escritores Le Corbusier e Camillo Sitte}

Le Corbusier (Suíça, 1887 - França, 1965), por ter sistematizado e divulgado o conjunto das ideias de sua geração, pode ser considerado o principal representante do modelo de pensamento progressista na arquitetura e no urbanismo. A divulgação de suas ideias contou com o valor intrínseco delas, com as particularidades do momento e do local onde foram geridas, e com a capacidade literária de seu autor: quase cinquenta livros e uma centena de artigos com relatos de viagens, transcrição de conferências, defesa de princípios, catálogos de exposição e exposição de pontos de vista: "he liked to think of himself as a poet of

\footnotetext{
${ }^{5}$ Discussions of systems of city planning figure among the burning issues of our day. On this, as on all topical matters, opinions are frequently at considerable variance. However, one can observe a widespread satisfaction with that which has been so well accomplished along technical lines - in respect to traffic, the advantageous use of building sites, and, especially, hygienic improvements. In contrast there is almost as prevalent a condemnation of the artistic shortcomings of modern city planning, even scorn and contempt. This is quite justified; it is a fact that much has been accomplished in technical matters, while artistically we have achieved almost nothing, modern majestic and monumental buildings being usually seen against the most awkward of public squares and the most badly divided lots.
} 
relationships, an inventor of neologisms, who enjoyed word plays such as Dom-Ino or utilized projective analogies such as a Machine à Vivre..." (Boyer, 2013: 21).

Suas ideias e concretizações receberam um volume ainda maior de textos, defendendo-as ou criticando-as. Em L'architettura moderna dopo la generazione dei Maestrí, Rogers (1956) analisa a influência do que chamou de as quatro estrelas de primeira grandeza no firmamento artístico de sua geração, citando nominalmente Le Corbusier, Frank Lloyd Wright, Walter Gropius e Mies van der Rohe. Na explicação de tamanha popularidade, temse ainda o caráter tratadista das suas obras, característica fundamental que estabelece sínteses, sugere polêmicas, facilita a difusão em geral e a assimilação pelo leitor.

A paixão e a prolixidade em relação à escrita fazem de Le Corbusier um objeto de dupla análise: pela perspectiva da obra e pela perspectiva de sua própria análise, desmesuradamente prolixa e confiante. Na primeira citação a seguir, tem-se clara a paixão de Le Corbusier pela escrita; na segunda, ao se referir ao papel dos urbanistas, tem-se a demonstração de confiança nos seus princípios.

O jovem Charle-Édouard Jeanneret é tão apaixonado pela escrita que após sua naturalização francesa, ele exige que se mencione como profissão, sobre sua carteira de identidade, "homem de letras". Quando de seu pedido por um visto para uma viagem à Suíça, em 1943, ele declara "arquiteto-escritor" (Jenger, 2001: 9). Tradução do original francês pelos autores ${ }^{7}$.

[...] organiza os espaços arquiteturais, fixa o lugar e a destinação dos continentes construídos, liga todas as coisas no tempo e no espaço por meio de uma rede de circulações. E [...] o arquiteto, ainda que interessado numa simples habitação e, nesta habitação, numa mera cozinha, também constrói continentes, cria espaços, decide sobre circulações. No plano do ato criativo, são um só o arquiteto e o urbanista (Le Corbusier, 2013: 14).

Nas comemorações do cinquentenário da morte de Le Corbusier, a sua palavra parece, justificadamente, constituir a fonte principal de investigação. Exposição Le Corbusier, mesure de I'homme (Centre Pompidou, Paris, 2015) revela não apenas as obras do homenageado em seus cinquenta anos de morte, mas sobretudo as oposições da crítica que elas provocaram; entre os livros nesta data, a investigação prioriza o homem em detrimento da obra. Chaslin (2015), por exemplo, a partir de uma densa leitura de textos de Le Corbusier, em Un Corbusier, reconstrói um universo de relações pessoais e profissionais e

\footnotetext{
${ }^{6}$ Publicado em português em 1960 como A Arquitetura Moderna desde a Geração dos Mestres (Livraria Sousa \& Almeida, Portugal).

${ }^{7}$ Le jeune Charles-Édouard Jeanneret aime tellement l'écriture qu'après sa naturalisation française, il fera mentionner como profession, sur sa carte d'identité, " homme de lettres ». Lorqu'il demande un visa pour un voyage en suisse, en 1943, il précise «architecte-écrivain » (Jenger, 2001: 9).
} 
conclui que o arquiteto teria sido "autor de sua própria fiç̧ão". De Jarcy (2015), em Le Corbusier, un fascisme français, estabelece no título a conclusão de seu trabalho. Perelman (2015), com Le Corbusier, une froide vision de monde, apresenta um arquiteto fascista, racista e temivelmente visionário em relação àquilo que a história traria. A crítica mais completa, entretanto, a que contempla a obra, a ideia e o texto de Le Corbusier é feita por Hall (2014) que afirma serem os livros do arquiteto pouco lidos; mais que isso, justifica o "desinteresse" pela "simples razão de que são inelegíveis". De fato, parágrafos excessivamente curtos observados nas duas obras do autor, muitas vezes dificultam ou inviabilizam sua compreensão: “Ano de 1943, sem caráter especial, situado, talvez, no ponto de inflexão entre a soma dos erros e a aurora da renovação" (Le Corbusier, 2013: 16).

Os livros Planejamento Urbano e Urbanismo - cujas alterações nos títulos em português mereceriam uma discussão específica - fazem parte, pois, de uma produção bibliográfica extensa de um arquiteto-escritor e que, por isso mesmo, já constituiriam um merecedor de atenção (Semett, 2005). A essa produção singular Choay (2005) reage com ceticismo, afirmando que nada lhe é "inaugural", fragilizando um dos atributos que mais interessavam a Le Corbusier.

Camillo Sitte (Áustria, 1843 - Áustria, 1903), arquiteto que influenciou as cidades-jardins inglesas e o urbanismo culturalista anglo-saxão, preconiza soluções por ele entendidas de escala e caráter humanos. Seria inspirado, ao contrário de Le Corbusier e demais progressistas, pela história e tradições. A construção de sua cidade ideal buscava livrar-se do sistema moderno de alinhamento regular de casas, salvar o que resta das cidades antigas, e aproximar ao máximo as criações atuais do ideal de modelos antigos (Choay, 2005). Essa seria a ideia central de Sitte (2006) na sua obra referencial, escrita em 1889.

\footnotetext{
Hoje, é regra fazer duas vias se interceptarem em ângulo reto em cada esquina de uma praça [...]. Mais precisamente, a regra contrária foi seguida em tempos anteriores [...]. O segredo consiste no fato de que as vias transversais são projetadas em ângulos de nossa visão e não de modo paralelo a elas. (Sitte, 2006: 171-172). Tradução da versão em inglês pelos autores ${ }^{8}$.

A busca pela simetria virou uma obsessão. Atualmente, o termo simetria está na boca de qualquer pessoa minimamente culta, e todo mundo se sente chamado a opinar sobre dificuldades artísticas como as do planejamento urbano porque elas
}

\footnotetext{
${ }^{8}$ Today it is the rule to let two streets intersect each other at right angles at each corner of a public square [...]. Precisely the opposite rule was followed in former days [...] The whole secret consists in the fact that entering streets are laid out at an angle to our lines of sight instead of parallel to them (Sitte, 2006: 171-172).
} 
já têm o discurso pronto sobre a regra basilar, a da simetria (Sitte, 2006: 189). Tradução da versão em inglês pelos autores ${ }^{9}$.

Tais conclusões seriam buscadas no estudo do espaço urbano antigo e medieval, sobretudo na relação entre construção, praças e monumento; no oposto, analisaria o padrão morfológico da cidade moderna, por ele considerada carente de princípios estéticos. $\mathrm{Na}$ valorização de uma cidade e na crítica de outra, passa de crítico à referência de destaque.

já em seu tempo, [Sitte] analisou e apontou falhas nos casos existentes cuja rigidez matemática e funcionalidade eram as diretrizes principais em detrimento do bemestar, padrões estéticos e da humanização [...]. O pensamento sitteano foi esquecido por um certo momento, mas hoje se encontra entre as referências mais importantes para quem trabalha e prioriza dados tanto de beleza quanto de fruição e apropriação do espaço pelo homem (Pedroso, 2005).

A produção textual de Sitte, ao contrário da de Le Corbusier, é significativamente menor e, assim como o é também a polêmica recebida. Sua atuação mais como teórico que autor de projetos arquitetônicos ou urbanísticos implementados talvez contribua para esse refluxo da crítica. Além disso, o texto de Sitte, mais conciliador, conforme confirmado em $A$ Construção das Cidades ..., igualmente colabora para esse fato. Tal texto é menos enfático e mais difícil de síntese, diferenciando-se da escrita mais assertiva de Le Corbusier. A despeito de sua clara apresentação de seus seis princípios em cada um dos seis primeiros capítulos da obra analisada, Sitte deixa espaço para uma "negociação" com o leitor.

A crítica sobre a obra de Sitte é igualmente "negociável", permitindo relativizações ao seu desejo de reprodução de um passado que não mais existe. Choay (1977: 121), por exemplo, reconhece Sitte como um teórico que rejeita afrontamentos sem deixar de reconhecer sua "paradoxale apparence de conservatisme". A leitura de A Construção das Cidades ..., todavia, identifica um Sitte que reconhece a cidade da Idade Média como feita sobre algo novo, espontaneamente, ou sobre vestígios de um assentamento pretérito, que a cidade da Renascença ensaia uma reconstrução e por isso deve ser rejeitada, do mesmo modo que a cidade Barroca, a qual lhe parece um rompante de adaptação. De fato, aquilo que the parece ser uma simples reprodução do passado assume uma crítica contundente a favor da originalidade.

Conclui-se que não apenas o caráter nostálgico de Sitte, na maioria das vezes alegado de forma simplista, pode ser relativizado, mas igualmente sua recusa em aceitar a ciência e

\footnotetext{
${ }^{9}$ Striving for symmetry has become quite the rage. Nowadays the term symmetry is on the tongue of every barely educated person, and everybody feels called upon to give an opinion on such difficult artistic problems as those of town planning because he has at his fingertips the single decisive rule - symmetry.
} 
tecnologias que seu tempo disponibilizou. No mesmo texto que propõe uma revisão da leitura mais tradicional feita sobre Sitte, Choay (1977) defende a ideia de que, de fato, o campo da estética está no centro das atenções de Sitte, porém, é inegável que ele não contesta a necessidade e o valor da ciência ou mesmo do conhecimento da biologia ou da sociologia em termos de obras urbanas. A abundância de trechos de seu livro que criticam a precisão da linha reta pode ser entendida como uma simples rejeição à técnica:

O mais importante [método moderno de planejamento urbano] são aqueles em grelha, o radial e o triangular [...]. Artisticamente falando, nem um deles têm interesse, isso porque em suas veias não pulsa uma única gota de sangue artístico (Sitte, 2006: 229). Tradução da versão em inglês pelos autores ${ }^{10}$.

Todavia, Sitte logo relativiza, afirmando que "the practical artist should not let himself be guided by sentimental impulses, because no artistic planning could be a thorough or lasting success unless it complied with modern living conditions (p.243)." A respeito dessa mesma questão, Le Corbusier é contundente na defesa da linha reta. Ao contrapô-la à "religião do caminho das mulas", estabelece o embate entre os autores:

O movimento partiu da Alemanha, consequência de uma obra de Camillo Sitte sobre o urbanismo, obra repleta de arbitrariedades: glorificação da linha curva e demonstração especiosa de suas belezas inigualáveis. A prova disso era dada por todas as cidades de arte da Idade Média; o autor confundia o pitoresco pictural com as regras de vitalidade de uma cidade (Le Corbusier, 1992: 9).

Tem-se como elementos potencializadores da polêmica, ou para aquilo que nos interessa mais, para a oposição entre Le Corbusier e Camillo Sitte, a forma escrita. Em Le Corbusier, a contundência e a síntese o expõe sobremaneira; em Sitte, o texto mais referenciado e mais "negociável" permite leituras distintas. Na superficialidade, Sitte seria categorizado como nostálgico e opositor a avanços necessários para a cidade, na profundidade, o revelam ousado para seu tempo. Anunciam-se, paradoxalmente, sinais de leituras em colisão, escritas distintas na forma e escritas dialógicas no conteúdo.

\footnotetext{
${ }^{10}$ The major [modern methods of city planning] are the gridiron system, the radial system, and the triangular system. [...]. Artistically speaking, not one of them is of any interest, for in their veins pulses not a single drop of artistic blood.
} 


\section{3. $O$ contexto das obras}

A despeito da clara inserção de Sitte e Le Corbusier como representantes do urbanismo, em oposição ao pré-urbanismo (Choay, 2005), seja pela formação de arquitetos, seja pela especialidade de ambos frente ao fenômeno urbano, seja ainda pelas suas claras intenções práticas na transformação do espaço, o ambiente profissional vivido por eles ainda é o de um campo de conhecimento em formação. A despeito dessa categorização, aos olhos atuais, as ideias por eles defendidas sugerem uma prolongada idade da inocência (referência à Wharton, 2004) ou mesmo uma reduzida capacidade de atualização em um mundo que acredita viver o fim das utopias urbanas (Ultramari, 2005). Assim, para o caso das obras aqui discutidas, a tipologia de Choay deve ser entendida pelo caráter processual daquilo que adjetiva, revelando mais sobreposições que rupturas: ora avançam para a compreensão de uma complexidade da realidade, ora retrocedem em seus princípios e soluções propostas, variando entre o descritivo, o polêmico, o utópico e a intervenção concreta. Do mesmo modo que hoje formulamos as teorias de urbanismo contemporâneo, passou-se então do pré-urbanismo ao urbanismo, com o segundo guardando traços remanescentes do primeiro (Julião, 2011) e, por meio de um processo interdiscursivo, submetendo-se à interlocução, às condições históricas e a um "já dito" e a uma "memória discursiva" (Pêcheux, 1997).

Na especificidade de Sitte e Le Corbusier, fica comum entre eles uma reação frente às novas relações sociais impostas pela industrialização e uma forçada distinção entre passado e futuro como referência. Com isso, pela perspectiva contemporânea, a mais correta distinção entre Sitte e Le Corbusier está menos na disputa entre o atual e o anacrônico, mas, sobretudo, no quanto e em quais as partes de seus discursos têm sido assimiladas.

As aproximações mais evidentes entre os dois são explicadas pelo contexto vivido comum. Primeiramente, o da exigência de respostas práticas e urgentes daqueles que abraçam o urbanismo como profissão, pretensa e aparentemente “despolitizando-os'. Ambos arquitetos, viam nos seus projetos uma autossatisfação e mesmo um determinismo da forma - para o primeiro - ou da função - para o segundo - sobre o comportamento do indivíduo e mesmo de sua organização social. 
Outra aproximação referente ao campo profissional, intelectual ou epistêmico é a chamada que recebem para participar ativamente dos seus momentos históricos: o primeiro, num posicionamento cívico e não necessariamente ideológico, na crítica veemente ao projeto de Otto Wagner para a Ringstrasse, em Viena, onde se veria a imagem de uma monarquia restaurada, e o fortalecimento da aristocracia, clero, exército e burguesia liberal; o segundo, por exemplo, teria confirmada sua aproximação com o fascismo e mesmo posições antissemitas; (Schorske, 1990).

\begin{abstract}
Hitler, afirma Le Corbusier, pode coroar sua vida por conta de uma obra grandiosa: a "organização da Europa". E tudo isso sob um velho antissemitismo [...]. Le Corbusier escrevera em junho de 1914: « O pequeno judeu um dia dominado [...]. Sempre avançado para seu tempo, e desde 1913, Le Corbusier já vomitava seu ódio: "esses judeus, cautelosos no fundo da raça deles, aguardam" (Perelman, 2015: 127). Tradução do original francês pelos autores ${ }^{11}$.
\end{abstract}

Tais similaridades os fazem homens de seu tempo, com ideias para contextos em que viviam, o europeu da industrialização e, no caso de Le Corbusier, de um pós-guerra ávido por reconstruções. Entretanto, a despeito desse evidenciado localismo, uma impressionante transferência de suas ideias, princípios e projetos são observadas em nível internacional e para realidades diversas que, por isso, podem relativizá-los, valorizá-los, desvalorizá-los ou renegá-los.

A universalidade buscada pelo urbanismo progressista - aqui confundido com o urbanismo modernista de Le Corbusier -, pensada a partir de uma realidade europeia, pode também, paradoxalmente, ser observada no urbanismo culturalista de Sitte. Este, ao defender a consideração das especificidades locais para o traço urbano, referencia-se numa cidade do passado que não existira em realidades externas à Europa. Na crítica ao traçado monumental da Ringstrasse de Otto Wagner, seria condescendente ao seu neoclássico e art-nouveau, estilos sabidamente não encontrados no passado urbano fora da Europa. Segundo Frampton (2003: 18), "nada caracteriza melhor a preocupação de Sitte em fazer esse reparo [as críticas às reformas "cenográficas" na Ringstrasse] do que sua comparação crítica da cidade 'aberta' de fins do século XIX, atravessada pelo tráfego, com a tranquilidade do núcleo medieval ou renascentista".

\footnotetext{
${ }^{11}$ Hitler, clame Le Corbusier, peut couronner sa vie par une œuvre grandiose : l'aménagement de l'Europe". Et tout ça sur fond d'un vieil antisémitisme. [...] Le Corbusier avait écrit en juin 1914 : "Le petit juif sera bien un jour dominé [...] Toujours en avance sur son temps, et dès 1913, Le Corbusier vomissait déjà sa haine : "Ces Juifs, cauteleux au fond de leur race, attendent.
} 
Houve, de fato uma colisão entre aquilo que acreditavam como verdade, mas o contexto vivido os levou a um tácito diálogo, remanescente nos tempos que lhes seguiriam, já com suas propostas transferidas e implantadas. Houve um forte desejo comum de universalismo, cada um a seu modo, praticável apenas pela imposição, e um igual vínculo com formulações utópicas de difícil consecução. Se, em vários momentos da leitura das obras selecionadas, há colisão de ideias entre Sitte e Le Corbusier; a oposição maior não estaria entre eles, mas sim entre as ideias de cada um e seus locais de recepção. Uma oposição geográfica (ideias para fora da Europa industrializada, do capitalismo avançado e da reconstrução no pósguerra em 1945) ou temporal (na defesa por seus defensores extemporâneos de uma permanência de um modelo de difícil aplicação na cidade contemporânea).

Finaliza-se este item com uma citação de Peter Hall, que, ao discutir os impactos, negativos, causados pela obra de Le Corbusier, nos confirma o cenário de florescimento das suas ideias: "Ideias criadas na intelligentsia da Paris dos anos 1920 veriam a ser aplicadas no planejamento para a classe trabalhadora de Sheffield e St. Louis, assim como em centenas de outras cidades, nos anos 1950 e 1960 ...". (2014: 205). Tradução do original em inglês pelos autores ${ }^{12}$.

\section{Continuidades, polêmicas e concordâncias}

Este artigo inicia com o pressuposto de que a discordância entre os princípios de Sitte e Le Corbusier seria uma evidência ostensiva. Antes de se chegar às considerações finais, observam-se posturas intermediárias e conciliatórias, as quais são evidenciadas mais pelo texto do primeiro que pelo do segundo. Weckzorek (1981) confirma essa evidência ao identificar hesitações e contradições sobre temas centrais no texto de Sitte que permitiriam ao leitor interpretações diversas. A redução da crítica à linha reta encontrada na obra de Sitte, desde que submetida à estética, é clara:

Uma ênfase especial é dada hoje em dia às vias retas de interminável extensão e particularmente na absoluta regularidade dos espaços públicos. Isto tem, no

\footnotetext{
12 “Ideas, forged in the Parisian intelligentsia of the 1920's, came to be applied to the planning working-class housing in Sheffield and St. Louis, and hundreds of other cities too, in the 1950s and 1960s..." (Le Corbusier, 2014: 205).
} 
entanto, pouca importância, e o esforço é inútil - minimamente em termos de objetivos artísticos (Sitte, 2006: 186). Tradução da versão em inglês pelos autores $^{13}$.

Isso confirma a atitude mais dialógica de Sitte, limitando ao nível do não-negociável apenas os valores artísticos, esses potencialmente subjetivos:

Assim era na Antiguidade, na Idade Média, na Renascença; de fato, em qualquer lugar que as artes fossem incentivadas. É apenas no nosso século matemático que o processo de crescimento e de projeto das cidades se tornou meramente técnico. Entretanto, parece importante que lembremos uma vez mais que essa atitude soluciona apenas um aspecto do problema, e que o outro, o aspecto artístico, é, no mínimo, tão importante quanto (Sitte, 2006: 142). Tradução da versão em inglês pelos autores ${ }^{14}$.

Encontrar aptidões à conciliação em Le Corbusier é tarefa árdua, seja devido à sua crença profunda nas suas próprias ideias, seja pela necessária arrogância de se fazer professoral e de intencionalmente não deixar dúvidas. A conciliação em relação à linha e ângulo retos encontrada em A construção da cidade ...., de Sitte, não se repete no litigioso Urbanismo, de Le Corbusier.

Hoje em dia, vias retas são necessárias e contam com importantes resultados. 0 que condenamos é seu uso automático, a priori, sem preocupação com a configuração do terreno ou outras especificidades locais. Se a linha curva é mais pitoresca, a reta é mais monumental; mas não podemos subsistir com a monumentalidade, apenas. Seria desejável que os construtores de nossas cidades atuais não abusassem nem de uma nem de outra, mas que a usassem adequadamente, de modo a dar a cada setor da cidade a conformidade com um determinado objetivo (Sitte, 2006: 205). Tradução da versão em inglês pelos autores $^{15}$.

O homem caminha em linha reta porque tem um objetivo; sabe aonde vai. Decidiu ir a algum lugar e caminha em linha reta.

A mula ziguezagueia, vagueia um pouco, cabeça oca e distraída, ziguezagueia para evitar os grandes pedregulhos, para se esquivar dos barrancos, para buscar a sombra; empenha-se o menos possível. (Le Corbusier, 1992: 5).

\footnotetext{
${ }^{13}$ A very special emphasis is placed nowadays on straight thoroughfares of interminable length and particularly on the absolute regularity of public squares, this is, however, quite unimportant, and the whole effort is expended useless - at least as far as artistic aims are concerned.

${ }^{14}$ Such it was in Antiquity, in the Middle Ages, in the Renaissance; indeed, wherever the arts were fostered. This is only in our mathematical century that the process of enlarging and laying out cities has become an almost purely technical concern. Therefore, it seems important to remind ourselves once again that this attitude solves only one aspect of the problem, and that the other, the artistic aspect, is of at least equal importance.

${ }^{15}$ Straight roads are necessary today and are often of very imposing effect. What we condemn is their mechanical employment, a priori, without concerning oneself with the configuration of the terrain or other local circumstances. If the meandering line is more picturesque, the straight one is more monumental; but we cannot subsist on monumentality alone, and it would be desirable that the builders of modern cities do not abuse the one or the other, but make use of them both as appropriate, in order to give to each district which they lay out as aspect in conformity with its purpose.
} 
O ângulo reto é como que a integral das forças que mantêm o mundo em equilíbrio. [...] o ângulo reto tem, portanto, direito sobre os outros ângulos: é único e constante (Le Corbusier, 1992: 20-21).

Ironicamente, se ressalvas não são feitas por Le Corbusier, essas podem ser encontradas em seus críticos, porém com o intuito de desconstruir princípios do arquiteto. Peter Hall (2014) em Cidades do Amanhã, por exemplo, desacredita o movimento modernista ao afirmar que nele há, sim, o adorno, fato que relativizaria a submissão da forma pela função em Le Corbusier e - provocativamente - o classificaria como "o último planejador do City Beautiful”.

Em seus últimos anos, ele [Le Corbusier] estava concentrado no complexo monumental central e simbolismo visual de modo geral, a questão de seus planos na qual ele tem mais maestria. Mas isso era apenas um ponto: ao final do dia, tal qual Hitler sonhando seus sonhos fúteis em Berlin, com o que ele realmente se preocupava era a parte monumental. Ele [Le Corbusier] foi o último dos planejadores do City Beautiful (Hall, 2014: 210). Tradução do original pelos autores $^{16}$

Tais relativizações, cabíveis para qualquer obra de referência e em diferentes campos do conhecimento social e cultural, justificam a redução da certeza com que na maioria das vezes os dois autores aqui estudados ou, de forma ampliada, as duas subcategorias estabelecidas por Choay (progressistas e culturalistas), são opostamente posicionados. A cidade contemporânea, nas suas distintas configurações internacionais e nas suas heterogeneidades intraurbanas, ao assimilarem partes de uma e de outra corrente, com mais ou menos adaptações, revelam ora uma convivência forçada, ora situações paradoxalmente complementares. Tal fato explicita a rejeição e inviabilidade de modelos únicos, universais, conforme pensados nas obras aqui analisadas e estabeleceriam, na prática, um inusitado diálogo entre Sitte e Le Corbusier.

A intencional universalidade das obras de Sitte e Le Corbusier é, pois, outro elemento de distinção e aproximação entre eles. A influência do meio em que foram formados e viveram na construção de seus princípios já foi discutido anteriormente; todavia, há diferenças no impacto que tal meio contou sobre um e outro autor. No caso de Le Corbusier, se tomarmos o fenômeno da industrialização como uma das principais bases referenciais de sua criação

\footnotetext{
${ }^{16}$ In his last years, he [Le Corbusier] had been concentrating on the central monumental complex and on the general visual symbolism, the part of the plan that works best. But that was just the point: at the end of the day, like Hitler dreaming his futile dreams in Berlin, what he really cared about was the monumental part. He [Le Corbusier] was the last of the City Beautiful planners.
} 
intelectual, essa teria, em diferentes temporalidades, uma consecução para além do território europeu. Ao se propor a responder como ferramenta possível para as reconstruções pós-guerra ou para um novo mundo que se urbanizava ou que se constituía em estados independentes, as chances de uma expansão das ideias de Le Corbusier eram verdadeiramente globais. Em Camillo Sitte, o vínculo com seu território natal o faz ostensivamente menos habilitado para uma universalidade. Collins e Collins (1965), por exemplo, enfatizam a importância sobre seu pensamento da sociedade teutônica da qual fazia parte, explicando a aproximação dos princípios de Sitte aos de uma arte como definidora de identidade nacional. Assim sendo, o próprio Sitte teria dificuldades em entender a arte e cultura universais ou a franco-suíça de Le Corbusier. Ao contrário, a intencionalidade internacional do modernismo proposto por Le Corbusier, o conhecido estilo internacional, não permite a identificação de qualquer proposta nacional. Mais que internacional, o modernismo se propõe universal, pretensamente capaz de atender aos interesses de diferentes geografias, e, merecedor das maiores críticas, de diferentes classes sociais. Adshed (1992: 204) sintetiza essa intenção e como ela a distingue de Sitte: "enquanto Camillo Sitte gosta de ver expressas todas as fraquezas da humanidade", o que indica sua valorização do localismo, "Le Corbusier ignora tal perversidade e supõe que todos os homens sejam totalmente disciplinados e idênticos", sugerindo um desejo e mesmo uma capacidade de se tornar universal.

Os fundamentos mais fortes que Sitte e Le Corbusier apresentam nas três obras reiteram essa diferença entre as condições de um e outro autor ter seus princípios pretensamente universalizados. Choay (2005), ao sintetizar as três condições básicas para se construir cidades segundo Sitte, confirma que não há aí uma universalidade do projeto e sim, de princípios: irregularidade dos blocos de casas alinhadas, salvaguarda daquilo que resta das cidades antigas e a semelhança das criações com modelos pretéritos. Valeria uma discussão sobre que cidades e modelos antigos Sitte se refere precisamente e qual seu entendimento da aplicação desses princípios em mundos com referenciais históricos distintos de sua Europa medieval. Do mesmo modo que Collins e Collins (1965), que nos falam de uma realidade germânica e nacional como referência principal a Sitte, Giedion (2004: 802) é incisivo ao afirmar que Sitte "havia perdido o contato com o seu tempo. O urbanista havia 
se tornado um trovador, lançando mão de canções medievais para competir com a balbúrdia da indústria moderna".

A crítica recebida pelas obras de Sitte e Le Corbusier pode, então, ser a maior distinção encontrada entre eles. Se a polêmica entre eles é reduzida na leitura aprofundada das três obras aqui em destaque, o que as relativiza, a crítica, paradoxalmente, é clara: contundente em relação a Le Corbusier e condescendente em relação a Sitte. Se, por um lado, as ideias de Sitte contam com mais chances de serem assimiladas meio a um ambiente contemporâneo de valorização da natureza, as de Le Corbusier já encontram justificativa no próprio estilo impositivo, tal qual um arauto de novos tempos a vir. Logo na introdução de Planejamento Urbano, essa pretensão é indiscutível: "Como evitar que nossas cidades se estendam, e se diluam, percam a forma e a alma? É o conjunto de problemas a que nos propomos responder no presente volume (Le Corbusier, 2013: 12). Objetos fáceis para a crítica são também as observações apressadas, fundidas na pretensão da singularidade histórica do momento por ele vivenciado:

Ébria de velocidade e de movimento, dir-se-ia que a sociedade toda se pôs, inconscientemente, a girar em torno de si própria; tal qual avião em parafuso dentro de uma bruma cada vez mais opaca. Dessa embriaguez só se escapa com a catástrofe, quando se fica pregado, pelo choque, no chão (Le Corbusier, 2013: 10).

A oposição entre uma obra, a de Sitte, onde é explícita a defesa da estética, e a do modernismo, onde há a crítica ao adereço e ao supérfluo, observam-se nuanças que se sobrepõem, seja, positivamente, em termos de um pretenso ineditismo, seja, negativamente, em termos de seus princípios. Para além de Hall (2014), que vê academicismo em Le Corbusier, a crítica a ele é encontrada em uma multiplicidade de autores, desde os seus contemporâneos como também aqueles que já enxergam o urbanismo modernista como uma proposta de um passado distante (vide Cidade e Jatobá, 2012). Do mesmo modo, Jatobá (2014) entende que os fundamentos da Carta de Atenas que contou com a mão forte de Le Corbusier - estão claros já nas teorias pré-socialistas de Owen, Godin e Fourier, no século XIX, e que a Cidade Industrial, de Tony Garnier, do início do Século XX já propunha a separação de funções urbanas, a valorização dos espaços verdes e o funcionalismo.

Outra perspectiva para se analisar similaridades e contrastes entre Sitte e Le Corbusier, além daquelas feitas sobre seus trabalhos e suas críticas, é pela discussão sobre como eles 
se veem um ao outro. A análise feita por Von Moos (2009: 213), sobre a crítica de Le Corbusier a Sitte abre uma primeira sugestão.

O ideal romântico e o pitoresco de um desenho urbano nas formas ao acaso que resultam do crescimento medieval das cidades é agora enfaticamente rejeitado. Esse fato, assim defendia Le Corbusier, tinha sido o principal erro de Camillo Sitte, "um vienense inteligente e sensível que, simplesmente, colocou o problema de modo errado". Traduzido do original em inglês pelos autores ${ }^{17}$.

Em termos projetivos, a distinção entre Sitte e Le Corbusier pode ainda ser estabelecida pelo modo como trabalham a cidade no plano, ignorando as diferenças de terreno e tomando a cidade como sua subjugada no segundo caso, e propondo, cuidadosamente, espaços públicos como um mosaico de particularidades no primeiro.

\begin{abstract}
Sitte nos mostrou que há princípios da construção urbana para além daqueles que resultam em execução de um plano pré-concebido. Ela avança, passo a passo, colocando cada peça com extremo cuidado em relação àquilo que já está feito. Seu método, se praticado com gosto e imaginação, produzirá um efeito pictórico e tornar-se-á algo histórico (Adshed, 1992: 2015). Traduzido do original em inglês pelos autores ${ }^{18}$.
\end{abstract}

Camillo Sitte viveu 60 anos; quando de sua morte, Le Corbusier tinha 16. O imaginado diálogo entre os dois teria acontecido 1) pela explicita discórdia a respeito da cidade industrial e de possíveis soluções para ela, seja progressista ou culturalista; 2) pela crítica retrospectiva de Le Corbusier a Sitte; e 3) pela leitura que hoje podemos fazer de seus trabalhos e da reprodução de suas ideias na prática. Um quarto diálogo ainda pode ser encontrado na relação do autor com sua própria obra: ambos escreveram objetivando a compilação daquilo que já haviam formulado anteriormente. Le Corbusier escreveu Urbanismo reproduzindo ensaios previamente publicados na Revista Esprit Nouveau. Planejamento Urbano igualmente estabelece princípios a partir de uma já longa produção arquitetônica do autor. Camillo Sitte escreveu A construção das cidades segundo seus princípios artísticos também como uma síntese de posições exaradas quando de seu envolvimento nas mudanças da Ringstrasse, em Viena. O olhar para suas próprias obras e inserções sócio-políticas aproxima mais uma vez os dois autores. Se aproximações são possíveis, reinterpretações da crítica que recebem também são repensadas, sobretudo se

\footnotetext{
${ }^{17}$ The romantic and picturesque ideal of a basic urban design on the random forms resulting from the growth of medieval cities is now emphatically rejected. This, so le Corbusier argued, had been the principal error of Camillo Sitte, "an intelligent and sensitive Viennese who simply stated the problem badly".

${ }^{18}$ Sitte showed us that there are principles of urban construction beyond those that result in the execution of a preconceived plan. It advances unit by unit, putting each with extreme caution in reference to what is already done. His method, if practiced with taste and imagination, will produce a pictorial effect and become a true story in stone.
} 
feitas na separação dos diferentes perfis que cada um deles exerceu. A ambivalência demonstrada por Lefebvre (1999) em relação a Le Corbusier nos ajuda a finalizar essa sessão. Para esse autor, os atributos que poderiam qualificar o arquiteto modernista variam entre um descompromissado título de advogado cartesiano do espaço abstrato ao de um brilhante arquiteto.

\section{Considerações finais}

A disputa entre as ideias apresentadas por um e outro autor aqui discutido ora parece pender para a vitória de um, ora para a definitiva prática de outro. A vitória e a derrota hipóteses descartadas já anteriormente ao início do artigo - ficam mais claras se analisadas distintamente no nível das ideias e no nível da prática do urbanismo ou gestão de cidades. Não há vitória ou derrota, há diálogos. Camillo Sitte popularizaria-se mais por meio de outros estudos que o analisam e menos por meio de seus próprios textos ou obra. 0 trabalho de Jane Jacobs, em Morte e Vida de Grandes Cidades (2000, primeira edição 1961) exemplifica essa assimilação. Ortegosa (2009) fala mesmo de uma revalorização do livro de Sitte neste período, após ser insistentemente rechaçado pelos Congressos Internacionais da Arquitetura Moderna (CIAM). Na sequência, Sitte parece ter permanecido ao resguardo de uma crítica mais contundente e protegido seja por um possível ineditismo, seja pela possível aderência de suas ideias com as de um urbanismo contemporâneo que defende o localismo e questões ambientais.

Em possível assimilação direta do trabalho de Sitte, e comumente referenciado na literatura científica contemporânea, pode-se citar também Marshall Berman (1986), com Tudo que é Sólido Desmancha no Ar, ao criticar as transformações no Bronx dos anos 1960 pelo prefeito Robert Moses. Do mesmo modo, a introdução da obra seminal de Jane Jacobs pode ser tomada como uma valorização de Sitte e uma crítica a Le Corbusier. Logo na introdução à Morte e Vida das Grandes Cidades, tem-se: "Este livro é uma ofensiva contra os princípios e objetivos que moldaram o planejamento urbano e reurbanização modernos ortodoxos" (2000: 1). 
Tais vitórias, todavia, sobrevivem a uma prática persistente iniciada em momentos imediatamente pretéritos a Camillo Sitte e que persistem em sua posteridade. Contra Sitte, no nível das ideias concretizadas, revelam-se exemplos icônicos para a história do urbanismo e frutos de uma Europa liberal, burguesa e capitalista que paradoxalmente Ihe serviram de insight ou mesmo inspiração: a Paris Haussmanniana da segunda metade do século XIX e a Ringstrasse em sua cidade natal, Viena. Na sua posteridade, também contra Sitte, têm-se a reconstrução de uma Europa pós-Segunda Grande Guerra e as novas cidades em um mundo periférico e neocolonizado. Porém, no nível da gestão urbana talvez repouse a derrota mais contundente das ideias de Sitte: a Carta de Atenas (1933), a qual imporia o caráter tratadista, funcionalista e generalizante concebido pelo urbanismo modernista em oposição a uma cidade que se faz "no desenvolver das coisas", por meio de planos de zoneamento e regulações de uso do solo.

A convivência entre derrotas e vitórias, ora de um modelo, ora de outro, parecem, pois, ser o cenário da cidade contemporânea, múltipla intrinsicamente. Em alguns momentos, no discurso da gestão, há sinais de uma defesa discursiva do homem que constrói a cidade; em outros, mais comuns, essa mesma gestão responde acriticamente a demandas de uma cidade ainda industrial, sempre em transformação e pouco afeita ao convívio comunitário. Para além da proposta do planejador urbano, tecnologias e modos sociais contemporâneos reforçam tais características e reiteram uma única cidade possível, aquela do indivíduo satisfeito em si mesmo. O paradoxo entre densidade urbana e isolamento social parece agora não mais resultar de uma opção de desenho da cidade e sim, sobretudo, de um novo homem: individualista e de relações sociais reformuladas, o habitante da cidade contemporânea desconsidera sua própria cidade e seus espaços públicos, como também parece desconsiderar a vida coletiva. Para esse morador, no seu cotidiano, a relação construção, praça e monumento perderam a força que tanto Sitte desejou.

A pergunta que teria distinguido os princípios defendidos pelo urbanismo de Camillo Sitte daquele de Le Corbusier, se o homem faz a cidade ou se a cidade faz o homem, tende agora a ser respondida pela constatação de um envelhecimento de ambos. Sennett (1999), dentre outros, com base em análises que começam no século XVIII, teria anunciado o cenário que esclarece essa questão. Para ele, a vida agora estaria marcada por um desinteresse na 
esfera pública das relações sociais, na prioridade da intimidade, da privacidade e da individualidade.

Se ambas as perspectivas sobrevivem, ainda que envelhecidas por razões que thes foram desconhecidas quando criadas, ainda é possível observá-las residualmente. Chaslin, (2015) ao se perguntar sobre a originalidade e responsabilidade do pensamento de Le Corbusier, afirma que este teria vencido "para o bem ou para mal":

Sua aposta [de Le Corbusier], aquela de um mundo novo e racional, triunfou para o bem e para o mal. Suas ideias se encarnaram na forma bastarda de grandes conjuntos. Seus amigos sempre afirmaram que ele não era responsável por isso, que esses conjuntos haviam sido construídos por seus inimigos, os arquitetos distinguidos pelo Prêmio de Roma $(s / n)$. Traduzido do original francês pelos autores ${ }^{19}$.

Igualmente, Sitte teria vencido, não necessariamente pela força de suas ideias, mas pela imposição de uma realidade; ou seja, uma vitória "circunstancial". O avanço das grandes cidades de países não centrais sobre áreas "não-planejadas", representaria uma ocupação ao acaso, ironicamente similar àquela defendida por Sitte, tal qual uma ocupação que se dá a golpes de demandas específicas e do momento. A espontaneidade defendida por Sitte tem como referência a cidade medieval; a cidade que aqui se toma como contemporânea é a que questiona a pretensão universal e tratadista do urbanismo funcional. A relação é arriscada, reconhece-se; porém, permanece a colisão entre o planejado e o de fato, entre a linha reta e a curva, entre o geral e o específico, entre o desejado e o ocorrido.

O fato de Sitte ter influenciado o planejamento urbano para melhor ou para pior ainda é um tema de discussão. Mas que seu impacto sobre a profissão foi instantâneo e profundo nunca foi questionada. O livro desse artista e crítico vienense exerceu uma influência para além de seus valores intrínsecos e dos do próprio autor entre outros arquitetos. (Collins and Collins, 2006: 19). Traduzido do original em inglês pelos autores ${ }^{20}$.

Nesta arriscada comparação, em final de artigo, resta-nos ainda pensar sobre a permanência da estética como elemento valorizado ou esquecido em nossa contemporaneidade urbana. O modernismo defendido na cidade pensada por Le Corbusier

\footnotetext{
${ }^{19}$ Son [de le Corbusier] pari, celui d'un monde neuf et rationnel, a triomphé pour le meilleur et pour le pire. Ses idées se sont incarnées dans la forme abâtardie des grands ensembles. Ses amis ont toujours affirmé qu'il n'en était pas responsable, que ces ensembles avaient été construits par ses ennemis, les architectes distingués par le Prix de Rome.
}

${ }^{20}$ Whether Sitte actually affected city planning for better or for worse is still today frequently disputed. But that his impact on the profession was instantaneous and profound has never been questioned. The book by this Viennese artist and critic exerted an influence far out of proportion to its size and so the position of its author among architects. 
rejeitara o traço guiado pela estética; hoje, esse traço é tacitamente rejeitado pela norma ambiental e pela espontaneidade das manchas urbanas. Para o urbanista de hoje tornam-se então incompreensíveis as críticas de Sitte aos seus contemporâneos, tais como aquela sobre a composição urbana feita por profissionais "correndo agitados com suas réguas T e seus compassos, acreditando resolver com geometria desajeitada os pequenos pontos que realmente interessam à essência de nossa sensibilidade" (Sitte, 2006: p. 158, tradução da versão em inglês pelos autores) ${ }^{21}$. Assim dito, é justificável a compreensão - a qual nos parece errônea - de que Sitte teria sugerido a reprodução da cidade do passado como resposta àquela que crescia ou mesmo de que teria subvalorizado aspectos referentes à salubridade, iluminação e ventilação. Atento a essa esperada crítica, o próprio Sitte já relativizaria seu respeito ao passado e, mais importante, sua deferência a um novo urbanismo que surgia. Mais de uma vez, nas páginas introdutória de seu trabalho, Sitte afirmara não desejar reproduzir a beleza pitoresca dos conjuntos urbanos antigos no ambiente de sua contemporaneidade, esclarecendo que a necessidade deveria ser a mestra de nossas decisões sobre a cidade.

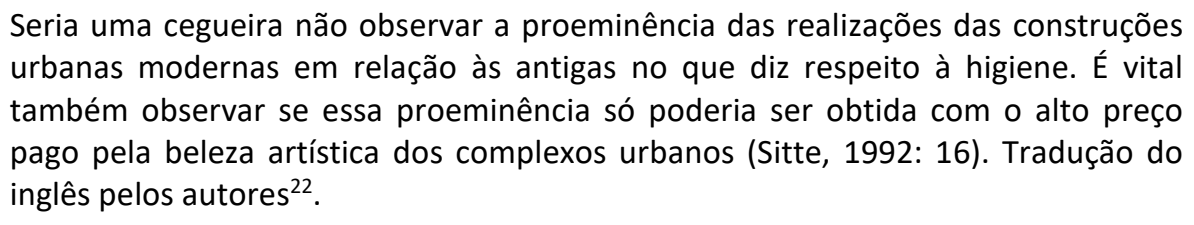

De acordo com Chalas (1998) sobre o que seria a cidade e o urbanismo contemporâneos, é possível observar uma história que, mais uma vez, tende a favorecer ora Camillo Sitte, ora Le Corbusier. Entre os atributos listados por Chalas destacam-se a perda de modelos de referência, o refluxo das utopias, e o declínio do planejamento. Ao contrário, confirmando a hipótese com que se iniciou este artigo, e mais voltado para uma realidade brasileira, o modelo modernista no urbanismo resiste não necessariamente pela sua estética, mas sim pelo seu espírito - desejadamente - funcionalista de zoneamento do uso do solo (Souza, 2002). Na identificação de reminiscências do culturalismo de Sitte, Jatobá (2014) o faz com crítica pelo fato de terem deixado seu legado na forma de um urbanismo pouco sustentável. Para este autor, a Cidade Jardim de Ebenezer Howard, teria inspirado não apenas as New

\footnotetext{
${ }^{21}$ Scurrying about with our T-square and compass, presuming to solve with clumsy geometry those fine points that are matters of pure sensitivity.

${ }^{22}$ It would be a kind of blindness not to notice the prominent achievements of modern urban construction in relation to the old ones with regard to hygiene [being still vital to know whether these advances] can only be obtained by the terrible price of resigning all the artistic beauty of urban complexes.
} 
Towns inglesas e o subúrbio norte-americano, mas também uma expansão urbana dispersa hoje observada em nível mundial e profundamente criticada por princípios de sustentabilidade. Por último, Matiello (2006) indica uma interessante aproximação entre os ditames do urbanismo defendido por Le Corbusier com o modelo de gestão urbana mais criticada atualmente no Brasil: aquela que é crente na capacidade máxima do Estado como regulador do solo urbano e propensa a ignorar aspectos intrinsecamente contraditórios da sociedade urbana.

Para além da crítica, interessou determinar a permanência de um e outro modelo, da sobreposição e defesa e da rejeição concomitante de Sitte e de Le Corbusier. Com permanências e envelhecimentos tem-se então o cenário de um urbanismo, não necessariamente forte, mas que se submete, obrigatoriamente, a distintas ordens e realidades complexas e cumulativas. Estaria aí, talvez, a crítica menos questionável que se pode fazer aos princípios de Camillo Sitte e de Le Corbusier: o de acreditarem na sua hegemonia.

\section{Referências bibliográficas}

ADSHED, S.D. Camillo Sitte and Le Corbusier, in: Town Planning Review, Vol. 14/15, 1930-33, pp. 85-95. Liverpool University Press.

BERMAN, M. Tudo que é sólido desmancha no ar: A aventura da modernidade, São Paulo: Cia. das Letras, 1986. BOYER, M. Christine. Le Corbusier, homme de lettres. New York: Princeton Architectural Press, 2013.

CAPES / Coordenação de Aperfeiçoamento de Pessoal de Nível Superior Banco de Teses e Dissertações. Disponível em http://catalogodeteses.capes.gov.br/catalogo-teses/\#!/ Acesso: 08/02/2018.

CHALAS, Yves. L'urbanisme comme Pensée Pratique, Pensée Faible et Débat Public. Annales de la Recherche Urbaine $n^{\circ} 80-81$, 1998. Disponível em http://www.annalesdelarechercheurbaine.fr/IMG/pdf/Chalas_ARU_8081.pdf Acesso: 03/01/17

CHASLIN, François. Le Corbusier a triomphé pour le meilleur et pour le pire. In Le 1 Hebdo, n. 54, abril de 2015. Disponível em http://Le1hebdo.Fr/Numero/54/Le-Corbusier-A-Triomph-Pour-Le-Meilleur-Et-Pour-Le-Pire903.Html. Acesso: 31/12/17

CHASLIN, François. Un Corbusier. Paris, Seuil, 2015

CHOAY, Françoise. O urbanismo: utopias e realidades, uma antologia. São Paulo: Perspectiva, 2005.

CHOAY, Françoise. Pour une nouvelle lecture de Camillo Sitte. Communications. Année 1977. Volume 27 , no 1. Paris: École des Hautes Études en Sciences Sociales, 1977.

CIAM. Carta de Atenas (1933). Disponível em: http://www.icomos.org.br/cartas/Carta_de_Atenas_1933.pdf Acesso: 10/03/2017. 
CIDADE, L.C.; JATOBÁ, S.U.S. Dinâmica social, modelos de urbanismo e seu rebatimento em questões ambientais. In: COUTINHO M. DA SILVA, R. (org.). Desafios Urbanos para a Sustentabilidade Ambiental nas Cidades Brasileiras. Rio de Janeiro: PROURB/UFRJ, 2012

DE JARCY, Xavier. Le Corbusier. Un fascisme français. Paris: Albin Michel, 2015.

COLLINS, George R; COLLINS, Christiane C. Camillo Sitte: The Birth of Modern City Planning. With a translation of the 1889 Austrian edition of his City Planning According to Artistic Principles. Mineola, New York: Dover Publications, Inc., 2006.

COLLINS, George R; COLLINS, Christiane C. Camillo Sitte y el Nacimiento del Urbanismo Moderno. Barcelona: Editorial Gustavo Gili, 1965.

FRAMPTON, Kenneth. História Crítica da Arquitetura Moderna. São Paulo: Martins Fontes, 2003.

FRANÇA, Eduardo Melo. Entre a Psicanálise e o Romantismo: a razão, o limite e a civilização. Acta Scientiarum. Language and Culture Maringá, v. 34, n. 1, p. 49-57, Jan.-June, 2012. Disponível em file://C:/Users/Cl\%C3\%B3vis/Desktop/9768-61688-1-PB.pdf Acesso: 02/01/2018.

GIEDION, S. Espaço, tempo e Arquitetura: O desenvolvimento de uma nova tradição. São Paulo, Martins Fontes, 2004

HALL, Peter. Cities of Tomorrow: an intellectual history of urban planning and design since 1880. Oxford: Blackwell, 2014.

HOBSBAWM, Eric J., Era dos Extremos: o breve século XX: 1914-1991. São Paulo: Companhia das Letras, 1995.

JACOBS, Jane. Morte e Vidas de Grandes Cidades. São Paulo: Martins Fontes, 2000.

JATOBÁ, Sergio Ulisses. A síndrome de Brasília: reflexões de um rótulo questionável. In Vitruvius, Resenhas online, no 146.02, ano 13, fev. $2014 . \quad$ Disponível em http://www.vitruvius.com.br/revistas/read/resenhasonline/13.146/5065 Acesso 25/03/2018.

JENGER, Jean. Le Corbusier: choix de lettres. Paris: Birkhauser, 2001.

JULIÃO, Raquel Manna. Memória e Interdiscurso no Urbanismo. Cadernos de História. Vol. 12, n. 16, 2011. Disponível em http://periodicos.pucminas.br/index.php/cadernoshistoria/article/view/P.22378871.2011v12n16p9 Acesso: 29/12/17

LE CORBUSIER. Planejamento urbano. São Paulo: Editora Perspectiva, 2013.

LE CORBUSIER. Urbanismo. São Paulo: Martins Fontes, 1992.

LEFÈBVRE, Henri. A revolução urbana. Belo Horizonte: Editora UFMG, 1999.

MANN, Thomas. Morte em Veneza. Rio de Janeiro: Nova Fronteira, 2000.

MARTIELLO, Alexandre M. Da Carta de Atenas ao Estatuto da Cidade: questões sobre o planejamento urbano no Brasil. Revista Impulso, 17(44): 43-54, 2006. Disponível em http://www.unimep.br/phpg/editora/revistaspdf/imp44art03.pdf. Acesso: 03/01/18.

NDLTD / Networked Digital Library of Theses and Dissertations. Banco de teses e dissertações. Virginia Tech University / VA Disponível em http://www.ndltd.org Acesso: 08/02/2018.

OATD / Open Access Theses and Dissertations Banco de teses e dissertações. Associação de instituições acadêmicas norte-americanas. Disponível em http://oatd.org Acesso: 08/02/2018.

PÊCHEUX, M. Semântica e Discurso: Uma Crítica à Afirmação do Óbvio. Campinas: Editora da UNICAMP. 1997.

PERELMAN, Marc. Le Corbusier, une froide vision de monde. Paris: Éditions Michalon, 2015.

ROGERS, Ernesto. L'architettura moderna dopo la generazione dei Maestri. Casabella Continuità n.211, vii, 1956.

SENNETT, Richard. O Declínio do Homem Público: as tiranias da intimidade. São Paulo: Companhia das Letras, 1999.

SCHORSKE, Carl. Viena fin-de-siècle: política e cultura. São Paulo: Companhia das Letras, 1990 
SITTE, Camillo. A construção das cidades segundo seus princípios artísticos. São Paulo: Ática, 1992.

SITTE, Camillo. City Planning According to Artistic Principles. In: COLLINS, George R; COLLINS, Christiane C. Camillo Sitte: The Birth of Modern City Planning. With a translation of the 1889 Austrian edition of his City Planning According to Artistic Principles. Mineola, New York: Dover Publications, Inc., 2006. p.129-332.

SMET, Catherine de. Le Corbusier, architect of books. Baden, Swiss: Lars Muller Publishers, 2005.

SOUSA, M. L. Mudar a Cidade: uma introdução crítica ao planejamento e a gestão urbanos. Rio de Janeiro: Bertrand Brasil, 2002.

ULTRAMARI, Clovis. O Fim das utopias urbanas. São Paulo: Nobel, 2005.

VON MOOS, Stanislau. Le Corbusier, elements of a synthesis. Rotterdam: Rotterdam Publishers, 2009.

WECKZOREK, Daniel. Camillo Sitte et les débuts de I úrbanisme moderne. Bruxelles: Mardaga, 1981.

WHARTON, E. The Age of Innocence. New York: Barnes and Nobel, 2004, first edition 1920. 